\title{
La "pretensión accesoria" de indemnización por daños y perjuicios en el proceso contencioso-administrativo
}

\section{Estanislao Arana García}

Catedrático de Derecho administrativo

Universidad de Granada

SUMARIO: I. PLANTEAMIENTO. II. EL EJERGICIO DE LA ACGIÓN DE RESPONSABILIDAD PATRIMONIAL Y EL CARÁCTER REVISOR DE LA JURISDICGIÓN CONTENGIOSO-ADMINISTRATIVA. III. LA GONFIGURACIÓN EN EL PROCESO GONTENGIOSO-ADMINISTRATIVO DE UNA PRETENSIÓN DE CONDENA A LA ADMINISTRACIÓN A INDEMNIZAR POR DAÑOS Y PERJUICIOS. 1. La indemnización por daños y perjuicios como "cuestión nueva" en el recurso contencioso-administrativo. 2. La indemnización por daños y perjuicios en recursos de plena jurisdicción. 3. La indemnización por daños y perjuicios no pretendida inicialmente en el recurso contencioso administrativo. 4. La indemnización por daños y perjuicios como pretensión principal del proceso contencioso-administrativo. IV. CONCLUSIONES: UN PASO MÁS HACIA LA DEFINITIVA SUPERACIÓN DEL CARÁCTER REVISOR DE LA JURISDICGIÓN CONTENCIOSO-ADMINISTRATIVA.

RESUMEN: El trabajo que presento analiza el contenido y alcance del Art. 31.2 de la Ley de la Jurisdicción Contencioso-administrativa en la medida en que permite adicionar como pretensión accesoria a la pretensión principal del demandante la de indemnización por daños y perjuicios en un único proceso. Planteo las consecuencias y particularidades de la admisión de esta pretensión frente al sostenimiento de la postura tradicional que mantenía la necesidad de ejercitar previamente en vía administrativa una reclamación de responsabilidad patrimonial.

Con el cumplimiento de los requisitos exigidos por la jurisprudencia delimitados y sistematizados en este trabajo, confirmo la posibilidad de solicitar en un mismo proceso y como pretensión accesoria, la indemnización de daños y perjuicios junto a otra pretensión principal. 
PALABRAS CLAVE: Indemnización por daños y perjuicios. Pretensión accesoria. Pretensión principal. Pleno restablecimiento de una situación jurídica individualizada. Responsabilidad patrimonial.

ABSTRACT: This paper analyzes the scope of Article 31.2 of the Spanish Administrative Procedure Act which leads to lodge, as an accessory claim linked to the main plaintiff, the compensation for damages in a unique process. As a result we discuss the consequences and particularities of admitting this type of secondary claim versus the more heterodox and traditional position that it forces to exercise a previous action in the administrative procedure through the action of public liability.

Based on arguments reached by jurisprudence as they are presented in this paper, I establish that is possible to request the compensation of damages by using this accessory action as a part of the main claim.

KEY WORDS: Compensation of damages. Accessory/secondary claim. Main claim. Fully redress of rights. Public liability.

\section{PLANTEAMIENTO}

Desde la aceptación de la teoría que identifica el objeto del proceso contencioso-administrativo con la pretensión formulada y no con el acto administrativo ${ }^{1}$, se ha podido entender abierta una brecha en la rígida y tradicional concepción de la Jurisdicción Contencioso-administrativa como una jurisdicción meramente revisora de los actos previamente adoptados por la Administración pública. El entendimiento de esta Jurisdicción desde esta óptica inicial parecía llevar más a considerar a la Jurisdicción Contencioso-administrativa como una segunda instancia a la vía administrativa que como un proceso, desarrollado por un verdadero "Poder" alternativo al ejecutivo en la tradicional tripartición de los poderes del Estado, ligado a la idea de hacer justicia.

$\mathrm{Y}$, precisamente, de entre todas las muestras de cambio que las diferentes aportaciones y novedades que la legislación reguladora de esta Jurisdicción ha ido introduciendo, sin duda, merece la pena destacar la que ofrece el artículo 31 de la actual Ley 29/1998, de 13 de julio, reguladora de la Jurisdicción Contencioso-Administrativa (LJCA, en adelante) que, tras aclarar que la declaración de no ser conformes a Derecho y la anulación de los actos y disposiciones administrativas son las pretensiones principales del demandante en el recurso contencioso-administrativo, abre la posibilidad de adicionar a dichas pretensiones la de solicitar la indemnización de daños y perjuicios. Literalmente, señala que el demandante "También podrá pretender el reconocimiento

Ilustrativa es, en este sentido, la doctrina del Tribunal Supremo, sobre todo a partir de su Sentencia de 23-10-1989, RJ 1989/7198. A partir de este momento, las Sentencias del Tribunal Supremo serán citadas con la abreviatura "STS". 
de una situación jurídica individualizada y la adopción de las medidas adecuadas para el pleno restablecimiento de la misma, entre ellas la indemnización de los daños y perjuicios, cuando proceda".

Este es, precisamente, el objeto de este trabajo, valorar la posibilidad y sistematizar los criterios y requisitos para solicitar en el mismo proceso contencioso-administrativo iniciado para lograr la anulación de un acto administrativo una condena a la Administración por los daños y perjuicios derivados de dicho acto, cuya anulación se pretende, como medida adecuada para el reconocimiento y restablecimiento de una situación jurídica individualizada. Lógicamente, a la par de la ampliación del objeto del recurso contencioso-administrativo que hace el apartado 2 del artículo 25 de esta LJCA, hemos de entender que estas consideraciones han de extenderse también a los supuestos en los que la pretensión principal del demandante en el recurso contencioso-administrativo no sea la anulación del acto sino, también, a los casos en que se condena a la Administración al cumplimiento de sus obligaciones en los concretos términos establecidos por una concreta normativa (inactividad administrativa) o la declaración de ser contraria a Derecho y el cese de la actuación administrativa que sea constitutiva de vía de hecho.

Partiremos de la clásica distinción jurisprudencial entre "recurso de anulación" y "recurso de plena jurisdicción", entendiendo por el primero aquél en el que la pretensión consiste, únicamente, en obtener la declaración de nulidad del acto o disposición impugnada que se entiende contraria a derecho, y por el de plena jurisdicción aquél recurso en el que, junto a la anulación, se pretende adicionalmente el reconocimiento de una situación jurídica individualizada y la adopción de las medidas adecuadas para su pleno restablecimiento, normalmente la indemnización de daños y perjuicios ${ }^{2}$.

Por otro lado, abordaremos el estudio de esta indemnización de daños y perjuicios en el proceso contencioso-administrativo desde diversas perspectivas: por un lado como medida de concreción de la pretensión de restablecimiento de una situación jurídica individualizada perturbada; por otro, como posible pretensión accesoria a la principal de anulación del acto, de condena al cumplimiento de la actividad no realizada o de declaración de la vía de hecho ilícita; finalmente, como pretensión principal, autónoma o independiente de otras pretensiones en el proceso contencioso-administrativo.

En cualquiera de los casos, intentaremos plantear las consecuencias y particularidades de la admisión de esta pretensión frente al sostenimiento de la postura tradicional que mantenía la necesidad de haber ejercitado previamente ante la Admi-

2 STS 14-12-1989 (RJ 1989/9130): “La pretensión procesal llamada de "plena jurisdicción” es aquella en que se solicita del órgano jurisdiccional no sólo la anulación del acto, sino el reconocimiento de una situación jurídica individualizada y la adopción de las medidas adecuadas para el pleno restablecimiento de la misma, entre ellas la indemnización de los daños y perjuicios cuando proceda ... por lo que viene condicionada a que se obtenga esa declaración de no conformidad a derecho de los actos administrativos de que se trate". 
nistración la conocida acción de responsabilidad patrimonial, actualmente regulada en el Capítulo IV de la Ley 40/2015, de 1 de octubre, de Régimen Jurídico del Sector Público (art. 32 a 37; en adelante LRJSP), y en la Ley 39/2015, de 1 de octubre, de Procedimiento Administrativo Común de las Administraciones Públicas que regula el procedimiento y las especialidades en de los procedimientos de responsabilidad patrimonial (arts. 65, 67, 81, 92; en adelante LPACAP).

\section{EL EJERCICIO DE LA ACGIÓN DE RESPONSABILIDAD PATRIMONIAL Y EL CARÁCTER REVISOR DE LAJURISDIC- GIÓN GONTENGIOSO-ADMINISTRATIVA}

La tarea encomendada a la Administración de lograr la satisfacción del interés general justifica que se le otorguen algunos privilegios. Entre ellos, el de la necesidad de someter a su consideración previa sus posibles ilegalidades como condición para poder acudir a la Jurisdicción Contencioso-administrativa. Como manifestación de ello se reguló, por ejemplo, la institución de la responsabilidad patrimonial que, desde un punto de vista procedimental, exige que con carácter previo a reclamar en vía judicial la indemnización por los daños o perjuicios que el funcionamiento de la Administración genera en los particulares, se tramite el correspondiente procedimiento administrativo frente a la propia Administración autora del daño.

Predicar rigurosamente el carácter revisor de la Jurisdicción contencioso-administrativa supondría, en consecuencia, el que en ningún caso pudiera plantearse judicialmente una cuestión nueva no suscitada y resuelta previamente en la vía administrativa. Sin embargo, la jurisprudencia ya había entendido que era posible pedir directamente en vía judicial contencioso-administrativa una indemnización, sin necesidad de ejercer previamente la acción de reclamación patrimonial, cuando el daño derivase directamente de actos administrativos impugnados en dicho orden jurisdiccional ${ }^{3}$ (aunque sin olvidar que la regla general seguía siendo la de agotar antes la vía administrativa).

Parece asumir así la legislación de procedimiento administrativo, en relación con las disposiciones de la LJCA, la teoría del carácter obligatorio de la reclamación administrativa previa de la indemnización por daños causados por la actividad de la Administración. En concreto, dispone el artículo 114.1 e) LPACAP que pone fin a la vía administrativa la resolución administrativa de los procedimientos de responsabilidad patrimonial, cualquiera que fuese el tipo de relación, pública o privada, de que derive. Y son precisamente los actos que ponen fin a la vía administrativa aquéllos contra los que es admisible, según dispone el artículo 25.1 de la LJCA, el recurso contencioso-administrativo.

\footnotetext{
$3 \quad$ STS de 23 de enero de 1991, RJ 1991/595 y de 25 de febrero de 1991, RJ 1991/1534, entre otras.
} 
En este sentido, el artículo 67.1 LPACAP establece que en los casos en que proceda reconocer derecho a indemnización por anulación en vía administrativa o contencioso administrativa de un acto o disposición de carácter general, el derecho a reclamar prescribe al año de haberse notificado la resolución administrativa o la sentencia definitiva.

Por otra parte, se insiste en esta idea cuando el artículo 32 LRJSP en sus apartados 4 y 5 prevé la procedencia de la indemnización: de un lado, si la lesión es consecuencia de la aplicación de una norma con rango de ley declarada inconstitucional, cuando el particular haya obtenido en cualquier instancia, sentencia firme desestimatoria de un recurso contra la actuación administrativa que ocasionó el daño y hubiera alegado la inconstitucionalidad posteriormente declarada; y, de otro lado, si la lesión es consecuencia de la aplicación de una norma declarada contraria al Derecho de la Unión Europea, cuando el particular hubiera obtenido, en cualquier instancia, sentencia firme desestimatoria de un recurso contra la actuación administrativa que ocasionó el daño, siempre que se hubiera alegado infracción del Derecho de la Unión Europea posteriormente declarada, debiéndose cumplir determinados requisitos, tales como que la norma tenga por objeto conferir derechos a los particulares, que el incumplimiento esté suficientemente caracterizado y que exista un relación de causalidad directa entre el incumplimiento de la obligación impuesta a la Administración y el daño. En estos dos supuestos, serán indemnizables los daños producidos en el plazo de los cinco años anteriores a la fecha de la publicación de la sentencia que declare la inconstitucionalidad de la norma con rango de ley o el carácter de norma contraria al Derecho de la Unión Europea, salvo que la sentencia disponga otra cosa (art. 34 LRJSP). En estos casos, el derecho a reclamar prescribe al año de la publicación en el BOE o en el DOUE, según el caso, de la sentencia que declare la inconstitucionalidad de la norma o su carácter contrario al Derecho de la Unión Europea.

En tal sentido, la inadmisión de la pretensión accesoria de condena por daños y perjuicios a la Administración por considerar que se trata de una cuestión nueva que requería haber agotado la vía administrativa o que mereciera su consideración como responsabilidad patrimonial es una interpretación, sin duda, anclada en la tradicional concepción de la naturaleza revisora de la Jurisdicción contencioso-administrativa. Esta interpretación ha ejercido su influencia en la jurisprudencia del Tribunal Supremo que entiende que en las respectivas sentencias de instancia, se debió declarar inadmisible el recurso respecto a la indemnización porque se trataba de una pretensión nueva respecto de la que la Administración no tuvo oportunidad de decidir. En este sentido, resultan de interés Sentencias como la del Tribunal Supremo de 16 de marzo de 2009 (RJ 2009/2488), en la que, existiendo una vía de hecho en la ocupación de una parcela por parte del Ayuntamiento, al haber sido reclamada la indemnización por primera vez en la demanda al impugnar la resolución valo- 
rativa del Jurado de Expropiación, el Tribunal entiende procedente desestimar la petición de indemnización por daños y perjuicios argumentando que se debió instar la oportuna reclamación por cauce administrativo al constituir ello una cuestión nueva sobre la que la Administración no tuvo ocasión de pronunciarse y al entender que el no incluir en la hoja de aprecio cantidad alguna en concepto de ocupación de la parcela constituye una manifestación de la responsabilidad patrimonial de la Administración, que tiene su propio y específico procedimiento en los artículos 139 y siguientes de la LRJPAC. En semejante sentido, la STS de 10 de junio de 2011 (RJ 2011/7032), en la que la Sala de instancia se abstiene de analizar aspectos que pudieran guardar relación con la pretensión indemnizatoria alegando que se trata de una cuestión que no había sido planteada ante la Administración ni ésta había tenido ocasión de pronunciarse sobre ella, desestimando, en consecuencia, el recurso de casación interpuesto. O, finalmente, la Sentencia del Tribunal Superior de Justicia de Andalucía, núm. 857/2012, de 22 junio (JUR 2012\307062), en la que se entendió que la pretensión que formulaba la parte recurrente constituye una manifestación de la responsabilidad patrimonial de la Administración y, por lo tanto, el cauce oportuno para sustanciarla habría de ser la vía administrativa.

Entendemos, sin embargo, que en estos supuestos se interpreta la pretensión de indemnización de daños y perjuicios ante el tribunal como cuestión principal o pretensión autónoma, sin ningún vínculo directo con la actuación impugnada ni derivadas de la anulación del acto o disposición impugnados. La cuestión que se plantea entonces y que pretendemos resolver a continuación es cuál sería el planteamiento más correcto en el caso de que la pretensión de indemnización de daños y perjuicios se anude o se vea supeditada a la obtención de una sentencia favorable respecto a la declaración de nulidad de un determinado acto administrativo impugnado, a la condena al cumplimiento de una obligación incumplida o a la declaración de una vía de hecho. Es decir, vamos a analizar el supuesto en que la solicitud de indemnización por daños y perjuicios en los juzgados y tribunales de lo contencioso-administrativo tiene carácter accesorio y no principal.

\section{LA CONFIGURAGIÓN EN EL PROCESO CONTENGIOSO-AD- MINISTRATIVO DE UNA PRETENSIÓN DE CONDENA A LA ADMINISTRACIÓN A INDEMNIZAR POR DAÑOS Y PERJUI- GIOS}

\section{La indemnización por daños y perjuicios como "cuestión nueva" en el recurso contencioso-administrativo}

Sobre la base del entendimiento de que en la pretensión podemos diferenciar entre la petición y la causa petendi (la pretensión se integraría así tanto por lo que se 
pide como por el conjunto de razones por las cuales se realiza esa petición y en las cuales se fundamenta) $)^{4}$, podríamos plantearnos si las pretensiones de las partes en el proceso contencioso administrativo acotan o delimitan el contenido del proceso y las posibilidades de decisión del órgano jurisdiccional desde ambas perspectivas; es decir, si no puede dilucidarse en vía jurisdiccional más pretensión que la formulada por las partes y conforme a los argumentos que las amparan en las correspondientes actuaciones de éstas. Y, aún más allá, si la pretensión en vía jurisdiccional queda o no delimitada por el requisito de la existencia de un acto previo de la Administración pública de tal manera que la Jurisdicción contencioso-administrativa no debería admitir la formulación de pretensiones que no hubieran sido objeto de resolución administrativa y respecto de las que, por lo tanto, la Administración no tuvo oportunidad de pronunciarse en el correspondiente procedimiento administrativo en cuanto a los dos ámbitos que la integran (la petición y los motivos fundamentadores de la misma).

En tal sentido, la jurisprudencia había realizado una interpretación de la causa de inadmisión del recurso contencioso administrativo prevista en el apartado c) del artículo 69 de la LJCA que permitía englobar en dicha causa genérica la desviación procesal, entendida ésta como la formulación en la vía jurisdiccional de pretensiones que no fueron objeto de tratamiento previo en la vía administrativa, incluso referidas al mismo acto administrativo impugnado. Así, en la STS de 15 de junio de 1992, por ejemplo, se dice que el planteamiento ante la Jurisdicción contencioso-administrativa de pretensiones no deducidas previamente en la vía administrativa (lo que ha venido denominándose "cuestión nueva") supondría desvirtuar el carácter revisor de ésta cuya finalidad es la de conocer de las cuestiones que previamente hubieran sido planteadas ante la Administración para valorar su ajuste o no al derecho ${ }^{5}$.

De este modo, la primera cuestión a la que debemos referirnos es la de si sería posible admitir en la vía contenciosa una pretensión referida a la indemnización de daños y perjuicios como cuestión nueva que no hubiera sido planteada con anterioridad ante la Administración mediante el ejercicio de la correspondiente acción de responsabilidad patrimonial.

El Tribunal Supremo, en alguna sentencia posterior a la anteriormente comentada, como la de 18 de febrero de 1999, relajó un poco esta exigencia al permitir al demandante aducir nuevas razones o argumentaciones de las peticiones, pero sin alterar tales peticiones, postura que asienta el Tribunal Constitucional en la Sentencia

4 "Objeto del recurso contencioso-administrativo. Capítulo II: Pretensiones de las partes", en Procedimiento y proceso administrativo práctico. Procedimiento contencioso-administrativo, Ed. La Ley, Dir. MORENO MOLINA, MASSÓ GARROTE Y PLEITE GUADAMILLAS, 2006, pág. 279.

Véase CUADRADO ZULOAGA, "La desviación procesal como causa de inadmisibilidad del recurso contencioso-administrativo", Actualidad Administrativa núm. 4, 2009, pág. 472. 
de 5 de julio de 2001 al considerar que, para que no exista desviación procesal, lo relevante es que no resulte alterada la causa petendi, lo cual no impediría, por lo tanto, que pudiera fundamentarse dicha causa en diferentes razones.

En esta línea, además, y sin olvidar lo comentado anteriormente respecto a la jurisprudencia previa a la Ley 30/1992 que justificaba la posibilidad de formular la pretensión accesoria de indemnización, la LJCA, en su Exposición de motivos, manifestó la voluntad de "superar la tradicional y restringida concepción del recurso contencioso-administrativo como una revisión judicial de los actos administrativos previos y de abrir definitivamente las puertas para obtener justicia frente a cualquier comportamiento ilícito de la Administración". El artículo 31.2 de esta Ley, como decíamos, estableció así que el demandante pudiera pretender, junto al reconocimiento de una situación jurídica individualizada, la adopción de las medidas adecuadas para el pleno restablecimiento de dicha situación. De este modo, este apartado parece así excepcionar la regla de inalterabilidad de las pretensiones e incluso el principio del carácter revisor del proceso, pues de su tenor se puede interpretar que dicha pretensión de resarcimiento no tendría que haber sido formulada obligatoriamente en la vía administrativa previa para poder ser ahora formulada en vía contenciosa como cuestión nueva o que las argumentaciones del demandante para acreditar los daños y perjuicios ocasionados por la Administración no hubieran tenido que ser previamente valoradas por la Administración.

Sin embargo, del literal de este precepto se nos plantearía una segunda cuestión de gran importancia en esta materia, en relación con el carácter o naturaleza autónoma o accesoria de la pretensión nueva de indemnización de los daños y perjuicios, pues, en atención al mismo, tendría que supeditarse la formulación de dicha pretensión (que tendría así carácter accesorio) a la formulación de otra (que sería la pretensión principal). La cuestión, por lo tanto, se centraría en dilucidar si, conforme a lo que establece la LJCA, sólo es viable la pretensión de indemnización como accesoria a otra principal o es posible su formulación como pretensión principal o autónoma.

Pero, efectivamente, de la lectura de este precepto podríamos plantearnos otras cuestiones adicionales al carácter o naturaleza accesoria de la pretensión de indemnización; es decir:

- si dicha pretensión es accesoria de la pretensión de reconocimiento de una situación jurídica individualizada, como medida adecuada para su pleno restablecimiento.

- si es simplemente una medida o forma de lograr el restablecimiento y, por lo tanto, un mero aspecto de dicha pretensión de reconocimiento de la situación jurídica individualizada, pretensión, ésta sí, que podríamos calificar como accesoria a la pretensión principal a que se refiere el apartado 1 (la declaración de no ser conformes a Derecho y la anulación de los actos y disposiciones administrativas). 
- o bien, finalmente, si dicha pretensión accesoria de indemnización lo sería respecto a las principales de anulación de actos o disposiciones administrativas (artículo 31.1), condena al cumplimiento de las obligaciones en casos de inactividad (artículo 32.1) o declaración de disconformidad a Derecho de la vía de hecho (artículo 32.2).

La jurisprudencia ha tratado esta cuestión acotando las posibilidades de introducción de esta "nueva pretensión" distinguiendo aquellos supuestos en los que la pretensión indemnizatoria (arts. 32 y ss. LRJSP) es la principal del proceso con objeto de obtener directamente el resarcimiento de daños y perjuicios causados por una actividad administrativa sin pasar, digámoslo así, por la vía administrativa, de aquéllos otros casos en los que la pretensión principal en el proceso sea alguna de las referidas en los artículos 31.1 ó 32 LJCA que, además, hubieran conllevado la causación de daños como consecuencia de su eficacia inmediata o ejecución.

Conforme a este planteamiento, creemos conveniente distinguir y sistematizar tres posibles situaciones que podríamos encontrar en relación con la cuestión nueva que supone la petición de indemnización de daños y perjuicios en el proceso contencioso administrativo:

a) la formulación de la pretensión de indemnización por daños y perjuicios en recursos de plena jurisdicción,

b) la posibilidad de resolver sobre la indemnización por daños y perjuicios en recursos en los que el demandante inicialmente sólo haya formulado la pretensión de anulación de actos administrativos, de condena al cumplimiento de sus obligaciones o de la declaración de disconformidad a Derecho de la vía de hecho, y

c) la formulación de la pretensión de indemnización por daños y perjuicios como pretensión principal o autónoma del proceso contencioso-administrativo.

\section{La indemnización por daños y perjuicios en recursos de plena jurisdicción}

En este primer supuesto nos referimos a la cuestión de si es viable la solicitud de indemnización por daños y perjuicios en el recurso contencioso-administrativo, como contenido de la pretensión de restablecimiento de una situación jurídica individualizada cuando dicha indemnización sea la forma o medida adecuada para dicho restablecimiento, con carácter accesorio a otra pretensión principal de anulación del acto administrativo disconforme a Derecho, de condena a realizar la actuación debida o de declaración de nulidad y cese de la vía de hecho, sin tener que acudir para ello previamente al procedimiento de responsabilidad patrimonial. Entraríamos de lleno, por lo tanto, en el supuesto al que, en principio, parece referirse el apartado 2 
del artículo 31 de la LJCA comentado, si bien dicho precepto merece algún comentario.

En este caso podríamos calificar a la petición de indemnización bien como una simple medida de las que refiere el precepto para lograr el restablecimiento de una situación jurídica individualizada, siendo pues el restablecimiento uno de los dos aspectos (el segundo) de una única pretensión de reconocimiento y restablecimiento de la situación jurídica individualizada, o bien calificarla como una pretensión adicional a otra de reconocimiento de una situación jurídica individualizada.

Desde este punto de vista, y atendiendo a los estrictos términos utilizados por el artículo 31.2, podríamos plantear la negación del carácter de pretensión a la indemnización de daños y perjuicios y entenderla únicamente como la forma práctica de dar satisfacción a la pretensión de reconocimiento y/o restablecimiento de una situación jurídica individualizada. De la lectura detenida del precepto entendemos, por lo tanto, que la pretensión (o más bien las dos pretensiones de ejercicio conjunto y consecuente), obviamente, serían el reconocimiento y restablecimiento de la situación jurídica individualizada que se hubiera visto vulnerada o lesionada de alguna de las siguientes maneras: por un acto administrativo, por la inactividad administrativa o por la actuación administrativa constitutiva de la vía de hecho. Otra cuestión sería dilucidar si esta pretensión de reconocimiento y restablecimiento de la situación jurídica individualizada es asimismo una pretensión principal o es accesoria a otra que podría consistir en la petición de la anulación del acto administrativo que afecta a la situación jurídica del demandante, en la petición de condena a la Administración a actuar en el sentido debido conforme a la normativa cuando no lo hubiera hecho (supuestos de inactividad: pasividad o inejecución de actos administrativos firmes) o en la petición de una declaración de la vía de hecho y la disposición de su cese.

Cuando la actuación administrativa (el acto administrativo o la disposición susceptible de impugnación) o la vía de hecho tengan como consecuencia la perturbación de una situación jurídica individualizada, los artículos 31.2 y 32.2 de la LJCA establecen expresamente la posibilidad de pretender "también" (dice el precepto) el pleno restablecimiento de dicha situación, expresión que tanto podría interpretarse en el sentido de considerar tal pretensión como adicional o anudada a la anterior, pero condicionada a la formulación de ésta, como en el sentido de considerarla simplemente una pretensión autónoma de formulación optativa. No hace alusión a esta posibilidad, sin embargo, el artículo 32.1 en relación con el recurso dirigido contra la inactividad de la Administración, que únicamente indica la posibilidad de pretender del órgano jurisdiccional una condena al cumplimiento de las obligaciones de la Administración, lo cual hemos de entender simplemente como un olvido normativo y no 
como un impedimento para el demandante en el caso de que la inactividad administrativa suponga también una alteración de una situación jurídica individualizada ${ }^{6}$.

Tal actuación o inactividad administrativa o la vía de hecho pueden ocasionar daños indemnizables, colocando pues al sujeto en una situación jurídica peor a la que tenía anteriormente. En tales casos, es obvio que una pretensión de restablecimiento de tal situación anterior debe comprender la compensación por la disminución patrimonial ocasionada por dicha actividad o inactividad dañosa. Incluso puede ser que la indemnización por daños y perjuicios sea la única medida posible para poder lograr el pleno restablecimiento de la situación jurídica perturbada por la actuación administrativa $^{7}$, como pudiera ser, por ejemplo, el caso de que se declare improcedente la demolición de un inmueble que ya haya sido ejecutada, o el supuesto de que el reconocimiento de un derecho no sea suficiente para el pleno restablecimiento, como ocurre cuando se reconoce el derecho de un funcionario a obtener una plaza o a continuar en el servicio activo pero no se le pagan los salarios dejados de percibir durante el tiempo transcurrido en la situación generada por la actividad ilícita o nula; o cuando se reconoce el derecho a la devolución de un dinero y se justifica que el haberlo entregado antes a la Administración ha impedido obtenerle una rentabilidad e incluso derecho a unos intereses por la devaluación natural del dinero.

La situación que se plantea en estos supuestos es una cuestión resuelta jurisprudencialmente desde hace tiempo, sobre todo respecto a los casos de reclamación de indemnización como medio de restablecimiento de situaciones jurídicas individualizadas perturbadas por la actuación material de la Administración constitutiva de vía de hecho (entre otras, la STS de 22 de marzo de 1999, RJ 1999/3159), si bien podemos considerar que la sentencia que marca claramente el sentido de la jurisprudencia en este supuesto es la STS de 22 de septiembre de 2003 (RJ 2003/6433, Rec. Casación 8039/1999) ${ }^{8}$. Esta sentencia parte de la diferenciación entre indemnización de

$6 \quad$ En contra de esta teoría, la STS de 22 de septiembre de 2003, en su FJ $2^{\circ}$ no hace alusión a esta posibilidad de pretender la indemnización en casos de inactividad administrativa al mencionar expresamente que "la solicitud de indemnización de los daños y perjuicios puede también acumularse en la vía jurisdiccional tanto a una pretensión de anulación de un acto administrativo como a una pretensión de cese de una actuación administrativa material constitutiva de vía de hecho". Sin embargo, una reciente sentencia, la STS 03/01/2013 (rec. 5273/2011), apoya nuestra interpretación, pues ha admitido también esta posibilidad en supuestos de inactividad. Así se desprende también del penúltimo párrafo del apartado V de la Exposición de Motivos de la LJCA.

GONZÁLEZ PÉREZ, J., Comentarios a la Ley de la furisdicción contencioso-administrativa, 6 a Edición, Civitas, Cizur Menor, Navarra, 2011, pág. 457. También STS 22/09/2000 y 6/07/2001: Cuando la satisfacción del derecho no sea posible, "se impone poner en juego el mecanismo de la indemnización de daños y perjuicios como remedio legal subsidiario para lograr la restauración del derecho perturbado.

$8 \quad$ Otras Sentencias en este sentido son la de 23 de octubre de 2000, la de 7 de julio de 2003, la de 19 de abril de 2007 (RJ 2007/3294, casación 7241/02, FJ 4º), o la de 16 de marzo de 2009 (RJ 2009/2488, recurso $7679 / 2005)$. 
daños y perjuicios como pretensión principal y como medida adecuada para obtener la plena indemnidad y sostiene que la pretensión de indemnización puede hacerse directamente ante el órgano contencioso en aquellos casos en que dicha indemnización sea el único medio de restablecimiento de la situación jurídica que la actuación material constitutiva de la vía de hecho, perturbó.

La conclusión que se obtiene de la doctrina jurisprudencial en este supuesto es que no es necesario haber solicitado la indemnización en la vía administrativa previa para poder plantear la solicitud de indemnización de daños y perjuicios como forma de restituir la situación jurídica individualizada, sobre la base del artículo 31.2 de la LJCA, formulándose dicha pretensión por primera vez en sede jurisdiccional.

En este caso, aunque no se hubiera pedido la indemnización en vía administrativa, podría formularse como cuestión nueva, no sólo en la demanda sino también, incluso, en la vista o en el trámite de conclusiones, según se desprende de lo indicado en el apartado 3 del artículo 65 LJCA, que señala que "en el acto de la vista o en el escrito de conclusiones el demandante podrá solicitar que la sentencia formule pronunciamiento concreto sobre la existencia y cuantía de los daños y perjuicios de cuyo resarcimiento se trate, si constasen ya probados en autos". Lo lógico, no obstante, es que la pretensión indemnizatoria se introduzca en la demanda pues difícilmente se esperará en la práctica al último momento procesal, salvo en casos específicos en los que haya clara notoriedad del daño, para probar la concurrencia de los daños y su evaluación.

Corroborando lo expuesto, la mencionada STS de 22 de septiembre de 2003, en su FJ $2^{\circ}$, indicaba que "la solicitud de indemnización de los daños y perjuicios constituye una pretensión singularizada en la LFCA por un régimen especial, conforme al cual puede interesarse, desde el principio, en vía administrativa, o puede también acumularse en la vía jurisdiccional tanto a una pretensión de anulación de un acto administrativo como a una pretensión de cese de una actuación administrativa material constitutiva de vía de hecho. $Y$ ello no sólo en la demanda, como medida adecuada para el restablecimiento de una situación jurídica individualizada..., sino incluso incorporando la petición en el momento de la vista o de las conclusiones, según el artículo 79.3 Lf/1956 (art. 65.3 LFCA de 1998). Posibilidad esta que responde a la concepción que tiene la Ley de la petición de indemnización de daños y perjuicios como una petición adicional de la pretensión de anulación del acto o de cese de la actuación constitutiva de vía de hecho, siempre claro está que los daños consten probados en autos".

Por otro lado, el olvido del artículo 32.2 nos impulsa a citar también un ejemplo en nuestra jurisprudencia en el que se señala la posibilidad de ${ }^{\mathbf{6}}$ deducirse sin que sea necesaria una previa reclamación a la Administración una pretensión por inactividad y una accesoria de indemnización". Es el caso de la STS de 3 de enero de 2013 (rec. 5273/2011). En dicha sentencia, la Universidad Complutense de Madrid solicitaba la ejecución del Plan de Inversiones en las Universidades Públicas de la Comunidad de Madrid para 
el ejercicio 2007-2011 y previsto para el 2010 y al mismo tiempo una indemnización por daños y perjuicios que se le ocasionaba a la propia Universidad como consecuencia de la inactividad de la Administración por la falta de ejecución de dicho plan. En síntesis, el Alto Tribunal lleva a cabo una interpretación del art. 32.1 LJCA según la Exposición de Motivos de la propia ley y estima el recurso de casación interpuesto por la Universidad, pues la LJCA no impide deducir esa pretensión accesoria de indemnización "porque esa configuración legal no es otra o distinta cuando la modalidad de la actividad administrativa impugnada lo es la nueva que introduce la LFCA y que denomina "inactividad de la Administración". Cierto es que la dicción literal del art. 32.1, y su puesta en relación con la de los artículos 31.2 y 32.2, todos de la LFCA, podría favorecer la interpretación de que cuando es esa la modalidad impugnada, sólo le cabría al demandante pretender del órgano jurisdiccional que condene a la Administración al cumplimiento de su obligación en los concretos términos en que esté establecida, sin poder añadir como accesoria una de condena a la indemnización de los daños y perjuicios derivados del incumplimiento. Pero no es así. De un lado, porque aquel párrafo de la Exposición de Motivos de la LFCA antes trascrito ${ }^{9}$, avisa que la nueva acción que deriva de esa modalidad no se atiene al tradicional carácter revisor del recurso contencioso-administrativo. $Y$, de otro, porque la indemnización de los daños y perjuicios causados forma parte del contenido mismo de la obligación, al establecer el art. 1101 del Código Civil ${ }^{10}$ que quedan sujetos a ella los que en el cumplimiento de sus obligaciones incurrieren en dolo, negligencia o morosidad, y los que de cualquier modo contravinieren al tenor de aquélla. O dicho en otras palabras, el cumplimiento de las obligaciones en los concretos términos en que estén establecidas, al que ciñe la pretensión el art. 32.1, comporta también, como inherente a él, la indemnización de los daños y perjuicios causados por dolo, negligencia o morosidad en dicho cumplimiento". En conclusión, al impugnar la inactividad de la Administración es posible pretender accesoriamente el restablecimiento de la situación jurídica individualizada a través de la medida de indemnización de daños y perjuicios como cuestión nueva en vía judicial.

\footnotetext{
$9 \quad$ Se refiere al penúltimo párrafo del apartado V de la Exposición de Motivos de la LJCA, en el que se lee: "En el caso del recurso contra la inactividad de la Administración, la Ley establece una reclamación previa en sede administrativa; en el del recurso contra la vía de hecho, un requerimiento previo de carácter potestativo, asimismo en sede administrativa. Pero eso no convierte a estos recursos en procesos contra la desestimación, en su caso por silencio, de tales reclamaciones o requerimientos. Ni, como se ha dicho, estas nuevas acciones se atienen al tradicional carácter revisor del recurso contencioso-administrativo, ni puede considerarse que la falta de estimación, total o parcial, de la reclamación o el requerimiento constituyan auténticos actos administrativos, expresos o presuntos. Lo que se persigue es sencillamente dar a la Administración la oportunidad de resolver el conflicto y de evitar la intervención judicial. En caso contrario, lo que se impugna sin más trámites es, directamente, la inactividad o actuación material correspondiente, cuyas circunstancias delimitan el objeto material del proceso".

10 Art. 1101 CC: Quedan sujetos a la indemnización de daños y perjuicios causados los que en el cumplimiento de sus obligaciones incurrieren en dolo, negligencia o morosidad y los que de cualquier modo contravinieren al tenor de aquéllas.
} 
En este mismo sentido el caso resuelto en la Sentencia del Juzgado de lo Contencioso Administrativo núm. 1 de Soria, de 31 de julio de 2017, que contempla un caso de inactividad del Ayuntamiento durante años, ante las molestias causadas a los vecinos por la instalación de una cancha deportiva abierta todos los días del año y sin ningún tipo de control, vulnerando los derechos a la integridad física y moral, a la intimidad personal y familiar y a la inviolabilidad del domicilio. Ante la petición en la demanda de una indemnización por daños y perjuicios y la oposición del Ayuntamiento por desviación procesal al no haberse efectuado esta petición en vía administrativa, el Juez, con apoyo en la Jurisprudencia (SSTS de 2 de julio de 2014, 3 de enero de 2013, entre otras), admite el recurso toda vez que la LJCA permite que una pretensión indemnizatoria se incorpore como complementaria o accesoria de la principal de anulación, sin necesidad de previa reclamación a la Administración causante del daño que directamente deriva de la actuación impugnada.

Es interesante también la Sentencia de 27 de marzo de 2014, del Juzgado de lo Contencioso-Administrativo de Murcia (RJCA 2014\469), en la que se impugna la desestimación por silencio administrativo de la solicitud formulada por la recurrente del abono de la prestación económica como cuidadora no profesional, así como, su alta en la Seguridad Social en el régimen correspondiente, pese al tiempo transcurrido desde el reconocimiento de la situación de dependencia de su progenitor a la fecha de su fallecimiento. Se trata de una desestimación presunta que es firme en vía administrativa, y las prestaciones solicitadas no fueron reconocidas en el procedimiento administrativo correspondiente ante el fallecimiento de la dependiente. Lo que lleva a la Administración demandada a entender que la reclamación de existencia de responsabilidad patrimonial de la Administración al haber fallecido la dependiente en el curso de la prolongada y morosa tramitación del procedimiento de reconocimiento del derecho a las prestaciones del Sistema de Atención a la Dependencia, es una acción de naturaleza extracontractual y fuera del procedimiento administrativo formalizado, consistiendo en una pretensión de indemnización por responsabilidad patrimonial por deficiente funcionamiento del servicio público, que ejercita la recurrente, por vez primera, en la demanda, no habiéndose formulado tal solicitud en vía administrativa, incurriendo en plus petición. El Juez resuelve, sobre la base de la STS de 15 de abril de 2008, que, aún cuando se plantea por vez primera en este recurso contencioso-administrativo la existencia de responsabilidad patrimonial, ello no supone ni plus petición, ni existencia de desviación procesal, toda vez que el artículo 31.2 LJCA permite su formulación en la demanda anudada a la declaración de nulidad de la actuación impugnada, sin necesidad de ese previo planteamiento ante la Administración.

Junto a ello, conviene precisar que no todo incumplimiento de plazos lleva consigo una responsabilidad patrimonial de forma automática. En este sentido, el Con- 
sejo de Estado indica que para que sean imputables a la Administración los daños producidos en la tramitación de un procedimiento, es preciso que este exceda de un período de tiempo razonable en atención criterios tales como la complejidad del asunto, la duración normal de procedimientos similares, etc. (Dictamen 449/2012, de 21 de junio).

\section{La indemnización por daños y perjuicios no pretendida inicialmente en el recurso contencioso administrativo}

Aclarada la cuestión de si se puede acumular accesoriamente a la pretensión de anulación de un acto administrativo la de que se condene a la Administración por los daños y perjuicios causados por la efectividad o ejecución de dicho acto cuya anulación se pretende, en el sentido de entenderla resuelta afirmativamente si el acto administrativo supuso la necesidad de restablecer la situación jurídica individualizada, procedería ahora plantearse el supuesto de que por la demandante se solicite la anulación del acto, condena a actuar o declaración y cese de la vía de hecho pero no se haya formulado inicialmente en la demanda la pretensión de indemnización de los daños y perjuicios.

Puede ocurrir que se haya formulado, en todo caso, la pretensión de restablecimiento de la situación jurídica individualizada, pero no se haya indicado que la forma de lograrla sea la indemnización por los daños y perjuicios o, incluso, que ni siquiera se haya hecho uso de la posibilidad que ofrece el artículo 31.2 y no se haya formulado la petición de restablecimiento de la situación jurídica individualizada. Pero, en cualquiera de estos casos, que de la tramitación del proceso se deduzca que el acto o la inactividad administrativa o la vía de hecho generaron unos daños al demandante que no ha reclamado previamente en la vía administrativa ni en la vía jurisdiccional contencioso-administrativa.

En el ámbito privado, el artículo 400 de la Ley de Enjuiciamiento Civil obliga a las partes a acumular en un solo proceso cuantas pretensiones puedan deducirse al tiempo de formularse la demanda, al establecer que habrán de aducirse en ella cuantos hechos y fundamentos o títulos jurídicos resulten conocidos o puedan invocarse al interponerla, sin que sea admisible reservar su alegación para un proceso posterior. Partiendo de ello, la correspondiente sentencia que resuelva el proceso no podrá, por motivos de congruencia, pronunciarse sobre cuestiones no controvertidas en el proceso, por lo que, de no solicitarse la correspondiente indemnización, la sentencia no resolvería al respecto de la misma. La congruencia es, en definitiva, un requisito de la sentencia, especialmente de su parte dispositiva, que "comporta la adecuación del fallo a las pretensiones formuladas por las partes y a los motivos aducidos por éstas ${ }^{11}$ ".

1 STS 23 junio de 2008, recurso 1523/2003. 
Sin embargo, la Jurisdicción Contencioso-administrativa deja al arbitrio del actor la acumulación de las pretensiones, lo cual puede deducirse de la redacción (podrá) de los artículos 31.2 y 35.1 de la LJCA. Concretamente, el artículo 35, tras exponer el 34 la posibilidad de acumulación de pretensiones que se deduzcan en relación con un mismo acto, disposición o actuación, ofrece al actor la "posibilidad" (no obligación) de acumular en su demanda dichas pretensiones. En conclusión, la Jurisdicción contenciosa es más flexible que la civil en este extremo, por lo que habríamos de entender que la interposición de un recurso contencioso-administrativo cuyo objeto sea un acto administrativo, inactividad o vía de hecho y respecto al que se haya ejercido una determinada pretensión no excluiría la posibilidad, en su caso, de reclamar la correspondiente indemnización por daños y perjuicios en un momento posterior (siempre que no hayan transcurrido los plazos de prescripción) y en un procedimiento administrativo o, en su caso, en un proceso contencioso-administrativo diferente.

Sin embargo, una vez interpuesto un recurso contra un acto, inactividad o vía de hecho en el que no se haya formulado la pretensión de restablecimiento de la situación jurídica individualizada, habría que valorar si el juez o tribunal, a la vista de las actuaciones, podría dictar una sentencia declarando la procedencia de la adopción de medidas de restablecimiento y, entre éstas, la indemnización por los daños y perjuicios que se hubieran acreditado en el proceso, si tal indemnización no se solicitó en la demanda.

El principio de congruencia de la sentencia también es reconocido en la Jurisdicción Contencioso-administrativa. Así, el artículo 67 de la LJCA exige la decisión de todas las cuestiones controvertidas en el proceso. La cuestión sería si es necesario entender que dicho principio de congruencia exigiría también que no se resuelvan otras que no sean las controvertidas en el proceso, como la lógica parece imponer y así ha sido interpretado por parte de la jurisprudencia. Precisamente la jurisprudencia considera que una sentencia incurrirá en incongruencia extra petitum si "concede algo no pedido o se pronuncia sobre una pretensión o una causa de pedir que no fue oportunamente deducida ${ }^{12}$. Y, la congruencia se resuelve en una valoración de la adecuación entre las pretensiones de las partes y la resolución del juzgador. Desde este punto de vista, y sin perjuicio de las valoraciones subjetivas que pudiéramos hacer al respecto, la interpretación jurisprudencial impediría inicialmente un reconocimiento judicial de la indemnización si ésta no ha sido una cuestión controvertida en el proceso.

No obstante, habría que valorar la posibilidad de distinguir dos situaciones, el que la indemnización haya sido expresamente solicitada en el recurso y el que se haya producido un debate sobre la existencia de daños y su valoración, como cuestión controvertida durante el proceso, sobre todo desde el entendimiento de la indemnización

12 STC 86/2000, 182/2000, 227/2000 y STS 22 de noviembre de 2001, de 15 de octubre de 2005 y 31 de enero y 11 de mayo de 2006 . 
de daños y perjuicios como una simple medida adecuada para lograr el restablecimiento de una situación jurídica individualizada, especialmente en los supuestos en que se haya formulado la pretensión de reconocimiento y restablecimiento de la misma sin indicar en la petición la forma concreta de lograrlo. En tal caso creemos que el juzgador sí podría sentenciar la indemnización de daños y perjuicios como forma de dar satisfacción a dicha pretensión de restablecimiento formulada cuando de la tramitación del procedimiento se deduzca que es la forma adecuada para ello y que se han acreditado los daños, su valoración y los requisitos legalmente establecidos para ello. En este sentido, puede resultar interesante la Sentencia del Tribunal Supremo de 18 de mayo de 2011 (RJ 2011/4448).

En caso de que no se hubieran acreditado y demostrado dichos daños, el actor tendría que acudir a la vía administrativa posteriormente para ello. No sería preciso, sin embargo, acudir a la vía administrativa si los daños han quedado demostrados en el proceso pero no ha sido cuantificada la indemnización, pues el artículo 71.1.d) de la LJCA permitiría declarar simplemente el derecho a la indemnización y el obligado a pagarla estableciendo las bases para la determinación de la cuantía concreta en el periodo de ejecución de sentencia.

En el otro supuesto, el de que no se haya formulado la pretensión de restablecimiento, entendemos que la sentencia deberá limitarse a declarar la anulación del acto, a condenar a la Administración al cumplimiento de las obligaciones debidas o a declarar el cese de la vía de hecho y no entrar a resolver las cuestiones atinentes a otras posibles pretensiones que el actor podría formular nuevamente, como decimos, en un procedimiento administrativo de reclamación patrimonial y/o en un posterior proceso contencioso-administrativo, habida cuenta del carácter potestativo con que la LJCA parece configurar dicha pretensión de restablecimiento y en aras a evitar la merma de garantías del lesionado que pudiera hacer valer en el momento oportuno. En tal caso, el reclamante dispondría nuevamente de un plazo de un año a contar, conforme al artículo 67.1 LPACAP, desde la notificación de la sentencia definitiva.

En este punto cabría plantearse también, sobre todo a la vista de lo dispuesto en el artículo 65.3 LJCA, si el hecho de que la pretensión de restablecimiento a través de la medida indemnizatoria no se haya formulado en la demanda pero sí posteriormente en el escrito de conclusiones o en la vista. Esta posibilidad abierta por el artículo 65.3 permitiría reconsiderar el concepto de "cuestión nueva" en el proceso contencioso-administrativo y flexibilizar las exigencias del principio de congruencia de la sentencia. En tal sentido, entendemos que no podría tacharse de incongruente una sentencia que declarase el reconocimiento de la situación jurídica individualizada y determinara las medidas de restablecimiento de la misma, aunque no se hubieran formulado tales pretensiones en la demanda, si se formulan posteriormente en la vista 
o en el escrito de conclusiones y siempre que los daños por los que se deba indemnizar constaran y quedaran demostrados en los autos.

A partir de aquí, y teniendo en cuenta esta "disponibilidad" del legislador contencioso-administrativo, podríamos aventurarnos también a valorar la posibilidad de admitir el debate jurisdiccional sobre la indemnización por daños y perjuicios no ya sólo como una cuestión nueva respecto a la vía administrativa, sino también como una cuestión nueva en relación con la primera instancia procesal, partiendo de la perspectiva de considerar dicha indemnización no ya como una pretensión sino como una medida que es necesario adoptar para lograr el restablecimiento de la situación jurídica individualizada en aras de lograr una resolución más justa, en el caso de que en la primera instancia no hubiera sido admitida la pretensión principal del recurrente y ésta sí hubiera sido reconocida posteriormente en el recurso.

Finalmente, podríamos hacer referencia en este apartado a dos cuestiones más. Una de ellas es la de si, por efecto de la cosa juzgada, en el caso de que se formule la pretensión de restablecimiento de la situación jurídica individual que conlleve la indemnización como pretensión adicional a la principal, por ejemplo, de anulación de un acto administrativo, y la resolución judicial contiene un pronunciamiento sobre dicha indemnización, el hecho de que se haya producido tal resolución judicial impediría volver a reclamar indemnización, e incluso una posible ampliación de la misma cuando se entienda que concurren circunstancias o daños respecto de los que no haya habido pronunciamiento judicial, en vía administrativa por daños que, pudiendo haberse reclamado, no fueron incluidos en la pretensión indemnizatoria anudada a la de anulación del acto causante de los perjuicios o que no resultaron debidamente acreditados en el proceso. Al respecto, creemos que, si los daños derivan directamente de la declaración de nulidad, ya no sería posible formular posteriormente la petición en la vía administrativa, pues la cosa juzgada supondría dar por sentado que habría quedado agotada la posibilidad de su planteamiento. Sin embargo, en el caso de que no exista una directa relación entre los perjuicios y la pretensión principal del proceso o en el caso de que no se hubiera formulado esta pretensión por parte del demandante, deberíamos entender viable el ejercicio posterior de la acción de responsabilidad patrimonial. De este modo surge la segunda cuestión, derivada de ésta, sobre los efectos de la tramitación del proceso Si se anula el acto en vía administrativa o judicial el plazo es de un año desde la notificación de la resolución o sentencia definitiva: art. 67.1 LPACAP.

\section{La indemnización por daños y perjuicios como pretensión principal del proceso contencioso-administrativo}

Por último, creemos procedente también valorar la opción hipotética de que el recurrente en el proceso contencioso-administrativo formule exclusivamente o como 
pretensión principal la de indemnización por daños y perjuicios derivados de un acto o disposición administrativa contrarios a Derecho, de una inactividad administrativa o de una actuación constitutiva de vía de hecho, pero sin formular las pretensiones que los artículos 31 y 32 señalan en relación con tales objetos del recurso.

Tanto de la legislación comentada hasta ahora como de la jurisprudencia estudiada parece que debemos entender que, en este caso, es necesario plantear previamente la solicitud de indemnización en vía administrativa. Diáfana resulta, sobre todo, la dicción de la mencionada Sentencia del Tribunal Supremo de 22 de septiembre de 2003, al decir que "la pretensión de indemnización de daños y perjuicios puede hacerse directamente ante el tribunal de lo contencioso-administrativo en aquellos casos en que sea el único medio de restablecer plenamente la situación jurídica que el acto administrativo o la vía de hecho perturbaron, pero cuando se articula como cuestión principal, sin ningún vínculo directo con la actuación impugnada, resulta necesaria la previa formulación de la petición en vía administrativa". También se han pronunciado en este sentido otras sentencias, como la del TSJ de Andalucía de 22 de junio de 2012.

Sin embargo, si tenemos en cuenta cuanto se ha argumentado hasta ahora respecto a la admisibilidad como cuestión nueva de la indemnización de daños como la principal medida para lograr el restablecimiento de situaciones jurídicas individualizadas, obviando la tradicional teoría del carácter revisor de la Jurisdicción Contencioso-administrativa, y realizamos una interpretación del texto del artículo 31.2 en el sentido de entender que la pretensión a que alude no hay que considerarla exclusivamente como accesoria a la del 31.1 sino como una pretensión más, alternativa, que puede formular el demandante en el recurso contencioso-administrativo, incluso de forma independiente, podría plantearse, de lege ferenda, un cambio que acoja esta interpretación para terminar convirtiendo la acción de responsabilidad patrimonial en la vía administrativa en una acción de carácter meramente voluntaria.

En la Sentencia del TSJ de Murcia de 18 de mayo de 2017 (JUR $2017 \backslash 187405)$, son dos las peticiones principales y no subordinadas, una consistente en que se iniciara expediente de expropiación y otra consistente en la retirada de escombros como pretensión de restablecimiento. De modo que "el restablecimiento o indemnización sustitutoria no se plantea como subordinada de la primera y debía haberse admitido a trámite. Como quiera que la Administración ha podido hacer alegaciones en el proceso y ha practicado prueba, no es aconsejable seguir una vía previa cuando existen datos y elementos en autos para considerar probada la existencia de tales residuos o vertidos".

Así también, Sentencia el TSJ de La Rioja, de 5 de octubre de 2017 (JUR $\backslash 2017 \backslash 293504)$, en relación al caso de quien fue perjudicado como consecuencia de no ser llamado a una interinidad, y en su lugar la ocupó otra persona que debió 
tener asignada menor puntuación; se desconoce el importe del daño, pero ello "no impide fijar las bases para que en ejecución de sentencia se reconozcan los efectos económicos y administrativos procedentes, abonándose al recurrente el importe de las retribuciones que debió percibir por el desempeño de la interinidad desarrollada....".

\section{CONCLUSIONES: HACIA LA DEFINITIVA REGONSIDERACIÓN DEL GARÁGTER REVISOR DE LA JURISDICGIÓN CONTEN- GIOSO-ADMINISTRATIVA}

El análisis llevado a cabo en este trabajo nos permite afirmar categóricamente la posibilidad de solicitar la indemnización de daños y perjuicios directamente ante la jurisdicción contencioso-administrativa en aquellos casos en que ésta sea la fórmula o medio de restablecer plenamente la situación jurídica que la actividad o inactividad administrativa o la vía de hecho perturbaron.

Sin embargo, cuando se articula como cuestión principal, sin vínculo directo con la actuación impugnada, es rechazada esta posibilidad y se entiende que resulta necesaria la previa formulación de la petición en vía administrativa a través del oportuno ejercicio de la acción de responsabilidad patrimonial y la tramitación del correspondiente procedimiento administrativo.

De la normativa y jurisprudencia estudiada podríamos deducir, por lo tanto, una serie de requisitos que actualmente configuran la viabilidad de esta pretensión ante la Jurisdicción Contencioso-administrativa, a saber:

- Que la indemnización de los daños y perjuicios sea el medio para lograr el restablecimiento pleno de la situación jurídica individualizada perturbada. Además, es especialmente receptiva la Jurisdicción a esta posibilidad cuando resulta imposible ya la restitución in natura como forma de restablecimiento de la situación jurídica.

- Que la indemnización ha de ser la consecuencia directa y natural de la anulación del acto, condena a actuación o declaración de la vía de hecho y de su cese, de manera que si el daño deriva de otros factores que no sean los determinantes de la sentencia, la pretensión de indemnización se ha de ejercitar de forma autónoma.

- Que dicha cuestión, aunque no haya sido tratada previamente en la vía administrativa, se haya planteado a lo largo del proceso y tanto los daños como los elementos determinantes de su evaluación (entendiendo que han de haberse justificado todos los requisitos establecidos en la legislación de régimen jurídico del sector público para la exigencia de responsabilidad 
patrimonial, según nos recuerda muy claramente la STS de 18 de mayo de 2011) consten probados en autos. Respecto a la determinación del quantum indemnizatorio, cabría la posibilidad de postergarla a la fase de ejecución de la sentencia por virtud de lo dispuesto en el art. 71.1.d) LJCA.

- Que, por exigencia del principio de congruencia, la indemnización de los daños haya sido solicitada, bien en la demanda, bien en el escrito de conclusiones o en la vista. La sentencia contenciosa incurriría en incongruencia extra petitum si concediera la indemnización o se pronunciara sobre ella sin haber sido oportunamente deducida.

En todo caso, la formulación de la referida pretensión ha de entenderse de carácter potestativo, pues ni el artículo 31.2 ni el 35 obligan a la acumulación de pretensiones en el proceso contencioso-administrativo, al contrario de lo que ocurre en el proceso regulado por la LEC. Por lo tanto, si es la voluntad del demandante, permanece abierta la vía de la reclamación patrimonial administrativa para satisfacer esta pretensión tras la resolución del primer proceso contencioso-administrativo.

Asimismo, hemos de entender interrumpido el plazo de prescripción a que se refiere el artículo 67.1 LPACAP en el supuesto de que se haya desarrollado un proceso contencioso-administrativo sobre la pretensión principal consistente en la anulación del acto administrativo, la condena de la Administración a cumplir sus obligaciones o al cese de la vía de hecho y no se haya anudado a tal pretensión la adicional de restablecimiento a que se refiere el artículo 31.2 o bien no se haya podido disponer durante el proceso de los elementos necesarios para su sustanciación. En caso contrario, la resolución judicial tendría efectos de cosa juzgada e impediría al reclamante un nuevo acceso a la vía ordinaria o a la jurisdicción en pretensión de la oportuna indemnización.

Por otro lado, la previsión del artículo 31.2 en la LJCA, apoyada por la propia Exposición de Motivos de dicha Ley y por una interpretación "pro actione" del precepto, parecen llevarnos a la conclusión de que esta posibilidad de formular la referida pretensión en el recurso contencioso-administrativo como accesoria a la principal que constituye el objeto inicial del recurso se constituye en una muestra fehaciente de la evolución de la naturaleza de la Jurisdicción contencioso-administrativa hacia la idea de unos juzgados y tribunales como órganos de tutela y no como meros revisores de la actividad administrativa a modo de segunda instancia administrativa. Junto a ésta, otras razones nos impulsan a pensar que ciertamente se está produciendo este cambio en la naturaleza de la Jurisdicción contencioso-administrativa:

- El hecho de que, según la Exposición de Motivos de la LJCA, la agilización de la tramitación de las causas es una de las preocupaciones dominantes en esta Jurisdicción. 
- La escasa posibilidad de justificación en una sociedad moderna del sometimiento de los mismos justiciables a diferentes procesos y de provocar la correspondiente actividad de los órganos jurisdiccionales, cuando la cuestión o asunto litigioso razonablemente puede zanjarse en uno sólo, sobre todo a la luz del Principio de economía procesal.

- El derecho a la tutela judicial efectiva, que impone la interpretación más favorable al ejercicio de la acción contenciosa por parte de los órganos jurisdiccionales, traducida en que ha de evitarse la denegación de justicia efectiva por interpretaciones formales rigoristas (STG 224/2001 o 252/2000). Especial relevancia cobra este derecho en el caso de la solicitud de indemnización en el recurso contencioso contra la vía de hecho ${ }^{13}$.

Por lo tanto, una vez abierta la puerta a la posibilidad del ciudadano de obtener la tutela judicial efectiva en cuanto a sus pretensiones de restablecimiento de situaciones jurídicas individualizadas que deben alcanzarse mediante la correspondiente indemnización de daños y perjuicios, cabría concluir si tiene sentido mantener el carácter obligatorio de la previa reclamación patrimonial en vía administrativa para poder acudir a la Jurisdicción contenciosa. Se trata, somos conscientes, de una afirmación muy atrevida y que supone la alteración de uno de los paradigmas y postulados fundamentales sobre los que se asienta el Derecho administrativo de nuestro tiempo. Sin embargo, la pérdida del tradicional privilegio para la Administración de la necesidad de agotar la vía administrativa en favor de una tutela judicial más completa y eficaz para el ciudadano, pudiera merecer la pena.

En todo caso son cuestiones que no muestran más que la realidad de la evolución de esta joven Jurisdicción que, a través de previsiones normativas como la ahora estudiada, va adquiriendo cada vez mayor autonomía y madurez y una vocación más garantista en aras de lograr la tutela efectiva del ciudadano.

13 Así lo reconoce la citada STS 22/09/2003, al decir que "si fuera preciso formular la reclamación previa ante la Administración para solicitar procesalmente la indemnización de los daños y perjuicios, se verían sustancialmente mermadas las posibilidades de la impugnación jurisdiccional directa de las vías de hechos ya que sólo sería posible solicitar el cese de las vías de hecho con lo que no se lograría el pleno restablecimiento de la situación jurídica anterior a la producción de tales vías, y así dicha impugnación jurisdiccional directa sería imperfecta y consustancialmente insatisfactoria para cumplir con las exigencias del derecho a la tutela judicial efectiva. 